\title{
Recursive Identification of Systems with Noninvertible Output Nonlinearities
}

\author{
Jozef VÖRÖS \\ Faculty of Electrical Engineering and Information Technology, Slovak Technical University \\ Ilkovicova 3, 81219 Bratislava, Slovakia \\ e-mail:jvoros@elf.stuba.sk
}

Received: January 2008; accepted: October 2008

\begin{abstract}
The paper deals with the recursive identification of dynamic systems having noninvertible output characteristics, which can be represented by the Wiener model. A special form of the model is considered where the linear dynamic block is given by its transfer function and the nonlinear static block is characterized by such a description of the piecewise-linear characteristic, which is appropriate for noninvertible nonlinearities. The proposed algorithm is a direct application of the known recursive least squares method extended with the estimation of internal variables and enables the on-line estimation of both the linear block parameters and the parameters of some noninvertible nonlinearities and their changes. The feasibility of the proposed method is illustrated on examples of time-varying systems.
\end{abstract}

Keywords: nonlinear systems, recursive identification, Wiener model, noninvertible characteristics.

\section{Introduction}

Many dynamic systems with output nonlinearity may be represented by the Wiener model with a linear dynamic system followed by a nonlinear static block (Haber and Keviczky, 1999). The linear block of Wiener model is typically described by its transfer function or a FIR model. The characteristics of nonlinear blocks are generally approximated by polynomials, splines or other functions, and a large number of parametric and nonparametric identification methods have been presented (Bai, 2003; Bershad et al., 2000; Celka et al., 2001; Cerone and Regruto, 2006; Chen, 2006; Gerksic et al., 2000; Greblicki, 1997; Hasiewicz and Sliwinski, 2002; Hu and Chen, 2005; Janczak, 2005, 2007; Jeng et al., 2005; Korenberg and Hunter, 1999; Lacy and Bernstein, 2003; Lee et al., 2004a, 2004b; Nordsjö and Zetterberg, 2001; Park and Lee, 2006; Pawlak et al., 2007; Pupeikis, 2005, 2006; Sun et al., 2003; Wigren, 1993). However, in most cases the inverse or 'pseudoinverse' of the output nonlinearity is assumed by the identification using Wiener models.

Recursive identification methods are important for the property that they can be computed in real time. Hence, they may be used in on-line monitoring and analysis of generally time-varying processes, and also combined with on-line control strategies to produce adaptive control algorithms. Some of them were applied to the nonlinear systems of Wiener type in the above-mentioned papers. The author has not found any published work 
that addresses the recursive identification of Wiener models when the static nonlinearity is noninvertible and eventually time-varying.

In this paper a new recursive identification method is presented for dynamic systems having noninvertible output characteristics using the Wiener model with piecewise-linear nonlinearities. A special form of the Wiener model is considered where the linear dynamic block is given by its transfer function and the nonlinear static block is characterized by such a description of the piecewise-linear characteristic, which is appropriate for noninvertible nonlinearities (Vörös, 2002). The identification method is a direct application of the known recursive least squares algorithm (Ljung, 1987) extended with the estimation of internal variables. The recursive method enables the on-line estimation of the parameters of linear block transfer function and the parameters characterizing the noninvertible piecewise-linear nonlinearity and their changes during the process. The proposed method is illustrated on two examples of time-varying Wiener systems.

\section{Piecewise-Linear Characteristics}

Piecewise-linear characteristics are often encountered in control systems to describe processes operating with different gains in different input intervals (Kalaš et al., 1985). The output $y(t)$ of piecewise-linear characteristic according to Fig. 1 depends on the sign and magnitude of input $x(t)$ and can be written as

$$
\begin{aligned}
& y(t)= \begin{cases}m_{R 1} x(t) & \text { if } 0 \leqslant x(t) \leqslant D_{R 1}, \\
m_{R 2}\left[x(t)-D_{R 1}\right]+m_{R 1} D_{R 1} & \text { if } x(t)>D_{R 1} ;\end{cases} \\
& y(t)= \begin{cases}m_{L 1} x(t) & \text { if } D_{L 1} \leqslant x(t)<0, \\
m_{L 2}\left[x(t)-D_{L 1}\right]+m_{L 1} D_{L 1} & \text { if } x(t)<D_{L 1},\end{cases}
\end{aligned}
$$

where $\left|m_{R 1}\right|<\infty,\left|m_{R 2}\right|<\infty$ are the linear segment slopes and $0<D_{R 1}<\infty$ is the constant for the positive inputs, $\left|m_{L 1}\right|<\infty,\left|m_{L 2}\right|<\infty$ are the linear segment slopes and $-\infty<D_{L 1}<0$ is the constant for the negative inputs.

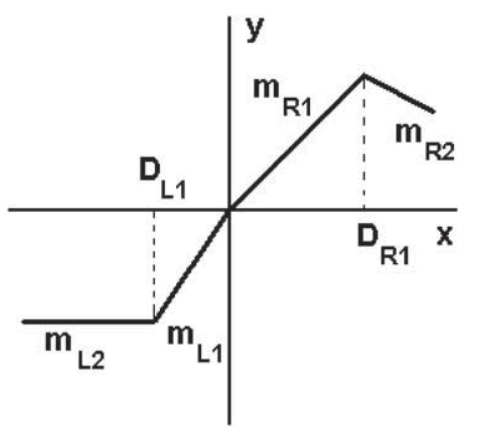

Fig. 1. Piecewise-linear characteristic. 
Using the description proposed in Vörös (2007) the piecewise-linear characteristic can be described in the following input-output form:

$$
\begin{aligned}
y(t)= & m_{R 1} x(t)+\left(m_{L 1}-m_{R 1}\right) h[x(t)] x(t) \\
& +\left(m_{R 2}-m_{R 1}\right) h\left[D_{R 1}-x(t)\right] x(t) \\
& -D_{R 1} f_{1}(t)+\left(m_{L 2}-m_{L 1}\right) h\left[x(t)-D_{L 1}\right] x(t)-D_{L 1} f_{2}(t),
\end{aligned}
$$

where the internal variables

$$
\begin{aligned}
& f_{1}(t)=\left(m_{R 2}-m_{R 1}\right) h\left[D_{R 1}-x(t)\right], \\
& f_{2}(t)=\left(m_{L 2}-m_{L 1}\right) h\left[x(t)-D_{L 1}\right],
\end{aligned}
$$

are generally unmeasurable and the switching function $h(\cdot)$ defined as follows:

$$
h(\alpha)= \begin{cases}0 & \text { if } \alpha \geqslant 0 \\ 1 & \text { if } \alpha<0\end{cases}
$$

switches between two sets of values, i.e., $(-\infty, \alpha)$ and $(\alpha, \infty)$. This form of piecewiselinear characteristic description is appropriate for the representation of noninvertible characteristics with saturations or negative slopes equally as in Vörös (2002).

\section{Wiener Model}

The Wiener model is given by a linear dynamic system followed by a static nonlinearity block and is shown in Fig. 2. The difference equation model of its linear block can be given as

$$
x(t)=A\left(q^{-1}\right) u(t-d)+\left[1-B\left(q^{-1}\right)\right] x(t),
$$

where $u(t)$ and $x(t)$ are the block inputs and outputs, respectively, $d$ is the time delay, $A\left(q^{-1}\right)$ and $B\left(q^{-1}\right)$ are scalar polynomials in the unit delay operator $q^{-1}$

$$
\begin{aligned}
& A\left(q^{-1}\right)=a_{0}+a_{1} q^{-1}+\cdots+a_{m} q^{-m}, \\
& B\left(q^{-1}\right)=1+b_{1} q^{-1}+\cdots+b_{n} q^{-n},
\end{aligned}
$$

where $m$ and $n$ are assumed to be known. Let the nonlinear block characteristic be given by (2.2). A direct substitution of $x(t)$ from (3.1) into (2.2) would result in a very complex expression containing cross-multiplied parameters and variables. To overcome this

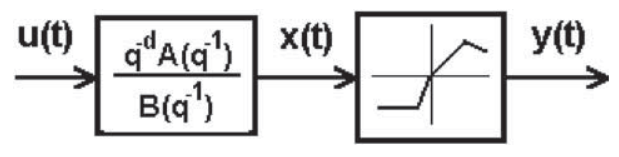

Fig. 2. Wiener model. 
problem, the key term separation principle can be applied to simplify the model equation (Vörös, 2007). Assuming that $m_{R 1}=1$ (this is always possible in the given system description), we separate the variable $x(t)$ as the key term of the nonlinear mapping (2.2). Then after the half-substitution of $x(t)$ from (3.1) into (2.2) (i.e., for the key term only), the system output is given in the form

$$
\begin{aligned}
y(t)= & A\left(q^{-1}\right) u(t-d)+\left[1-B\left(q^{-1}\right)\right] x(t)+m_{1} h[x(t)] x(t) \\
& +\left(m_{R 2}-m_{R 1}\right) h\left[D_{R 1}-x(t)\right] x(t)-D_{R 1} f_{1}(t) \\
& +\left(m_{L 2}-m_{L 1}\right) h\left[x(t)-D_{L 1}\right] x(t)-D_{L 1} f_{2}(t),
\end{aligned}
$$

where $m_{1}=m_{L 1}-m_{R 1}=m_{L 1}-1$. The output equation (3.4) and (2.3), (2.4) and (3.1) defining the internal variables $f_{1}(t), f_{2}(t)$ and $x(t)$ represent a special form of the Wiener model with piecewise-linear nonlinearities. This can be put into a concise form

$$
y(t)=\varphi^{T}(\theta, t) \theta
$$

where the data vector is defined as

$$
\begin{aligned}
\varphi^{T}(\theta, t)= & {[u(t-d), \ldots, u(t-d-m),-x(t-1), \ldots,-x(t-n), h[x(t)] x(t),} \\
& \left.h\left[D_{R 1}-x(t)\right] x(t),-f_{1}(t), h\left[x(t)-D_{L 1}\right] x(t),-f_{2}(t)\right]
\end{aligned}
$$

and the vector of parameters is

$$
\theta^{T}=\left[a_{0}, \ldots, a_{m}, b_{1}, \ldots, b_{n}, m_{1}, m_{R 2}-m_{R 1}, D_{R 1}, m_{L 2}-m_{L 1}, D_{L 1}\right]
$$

The Wiener model with piecewise-linear nonlinearities given by (3.4) has the minimum number of parameters, i.e., only the parameters characterizing the linear and nonlinear blocks are included into the output equation and not the combinations of these parameters. All of them enter the expressions linearly, except $D_{R 1}$ and $D_{L 1}$, which appear both linearly and nonlinearly.

\section{Recursive Identification}

The problem with the decomposed form of Wiener model given by (3.4) is that the internal variables $f_{1}(t), f_{2}(t)$ and $x(t)$ are not accessible for measurement. Therefore an iterative method was proposed for the batch identification of nonlinear systems using this model (Vörös, 2007). For the recursive identification, a new estimation technique is presented below combining the iterative and recursive approaches.

The estimates of the parameter vector $\hat{\theta}(t)$ can be evaluated using the RLS algorithm, minimizing the least-squares criterion based on (3.5), where the data vector $\varphi(t, \theta)$ is 
replaced by $\hat{\varphi}(t)$ with the estimates of the internal variable. The formulae of recursive identification algorithm are as follows:

$$
\begin{aligned}
& \hat{x}(t)=\sum_{i=0}^{m} \hat{a}_{i}(t-1) u(t-d-i)-\sum_{j=1}^{n} \hat{b}_{j}(t-1) \hat{x}(t-j), \\
& \hat{f}_{1}(t)=\left[\hat{m}_{R 2}(t-1)-\hat{m}_{R 1}(t-1)\right] h\left[\hat{D}_{R 1}(t-1)-\hat{x}(t)\right], \\
& \hat{f}_{2}(t)=\left[\hat{m}_{L 2}(t-1)-\hat{m}_{L 1}(t-1)\right] h\left[\hat{x}(t)-\hat{D}_{L 1}(t-1)\right], \\
& \hat{\varphi}^{T}(t)=[u(t-d), u(t-d-1), \ldots, u(t-d-m),-\hat{x}(t-1), \ldots, \\
& -\hat{x}(t-n), h[\hat{x}(t)] \hat{x}(t), h\left[\hat{D}_{R 1}-\hat{x}(t)\right] \hat{x}(t), \\
& \left.-\hat{f}_{1}(t), h\left[\hat{x}(t)-\hat{D}_{L 1}\right] \hat{x}(t),-\hat{f}_{2}(t)\right] \text {, } \\
& \hat{\theta}(t)=\hat{\theta}(t-1)+\frac{\hat{P}(t-1) \hat{\varphi}(t)\left[y(t)-\hat{\varphi}^{T}(t) \hat{\theta}(t-1)\right]}{\lambda+\hat{\varphi}^{T}(t) \hat{P}(t-1) \hat{\varphi}(t)}, \\
& \hat{P}(t)=\frac{1}{\lambda}\left[\hat{P}(t-1)-\frac{\hat{P}(t-1) \hat{\varphi}(t) \hat{\varphi}^{T}(t) \hat{P}(t-1)}{\lambda+\hat{\varphi}^{T}(t) \hat{P}(t-1) \hat{\varphi}(t)}\right], \\
& \hat{P}(0)=\mu I, \quad 0<\mu<\infty .
\end{aligned}
$$

The new values of internal variables for the data vector (4.4) in each recursion are computed according to (4.1)-(4.3) with the previous estimates of the corresponding parameters. The initial estimates of parameters can be chosen zero. However, nonzero initial values of $D_{R 1}$ and $D_{L 1}$ have to be considered for the first estimates of the internal variable $f_{1}(t)$ and $f_{2}(t)$.

The so-called forgetting factor $\lambda \leqslant 1$ can be effectively applied to reduce the influence of old data. Generally, the internal variable estimation requires the use of lower forgetting factor $\lambda$ to reduce the influence of old estimates, while a value of $\lambda$ close or equal to 1 is less sensitive to disturbances (Chidambaram, 2001; Ljung, 1987). A compromise may be to apply two values of forgetting factor: a lower one at the beginning of the recursive process and a higher one later.

\section{Examples}

The method for the identification of Wiener systems with piecewise-linear nonlinearities was implemented and tested in MATLAB. Several Wiener systems were simulated and the estimations of all the model parameters were carried out on the basis of input and output records. The performance of the proposed method is illustrated on the following examples of time-varying systems.

EXAMPLE 1. The linear dynamic block of the Wiener system was described by the equation

$$
\left[1-0.3 q^{-1}+0.4 q^{-2}\right] x(t)=\left[q^{-1}+0.3 q^{-2}\right] u(t) .
$$


The nonlinear block was given by the original piecewise-linear characteristic (an asymmetric saturation - the thin line in Fig. 3) that was changed to the new one, i.e., characteristic with shifted constants $D_{R 1}$ and $D_{L 1}$ determining the nonlinearity domain partition and negative slopes (the thick line in Fig. 3). The corresponding sets of parameters are given in Table 1.

The changes of nonlinear block parameters occurred slowly and gradually in the time interval $t \in(2000,3000)$. The recursive identification was carried out for 5000 samples of uniformly distributed random inputs with $|u(t)|<1$ and generated process outputs $y(t)$ with additive noise. The noise was generated as a zero mean Gaussian white noise and the signal to noise ratio (the square root of the ratio of output and noise variances) was $\mathrm{SNR}=50$. The initial values of all the parameters were chosen zero, except $D_{R 1}(1)=$ 0.1 and $D_{L 1}(1)=-0.1$. Two forgetting factors were used in this example, i.e., $\lambda=0.94$ for 500 samples to reduce the influence the old estimates of internal variables at the beginning of recursion and $\lambda=0.99$ for the rest of data. The process of parameter estimation is graphically shown in Fig. 4 for the linear block parameters and in Fig. 5 for the nonlinear block time-varying parameters. It can be seen that the model parameter estimates are able to track the true parameters.

EXAMPLE 2. The linear dynamic block of the Wiener system was described by the equation

$$
\left[1-0.2 q^{-1}+0.35 q^{-2}\right] x(t)=\left[q^{-1}+0.5 q^{-2}\right] u(t)
$$

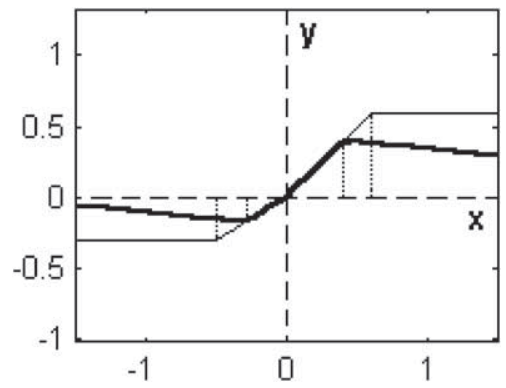

Fig. 3. Original (thin) and changed (thick) characteristic - Example 1.

Table 1

Parameters of the nonlinear block - Example 1

\begin{tabular}{lcc}
\hline Parameter & Original & Changed \\
\hline$m_{1}$ & -0.4 & -0.4 \\
$m_{R 2}-m_{R 1}$ & -1.0 & -1.1 \\
$m_{L 2}-m_{L 1}$ & -0.6 & -0.7 \\
$D_{R 1}$ & 0.6 & 0.4 \\
$D_{L 1}$ & -0.5 & -0.3 \\
\hline
\end{tabular}




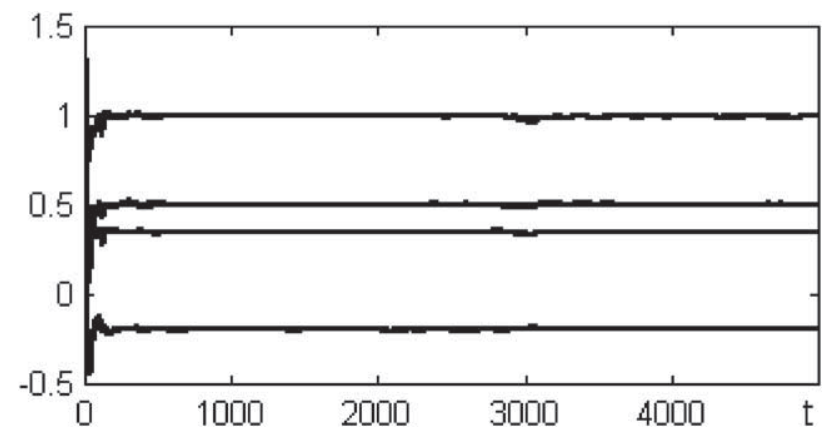

Fig. 4. Estimates of the linear block parameters - Example 1.

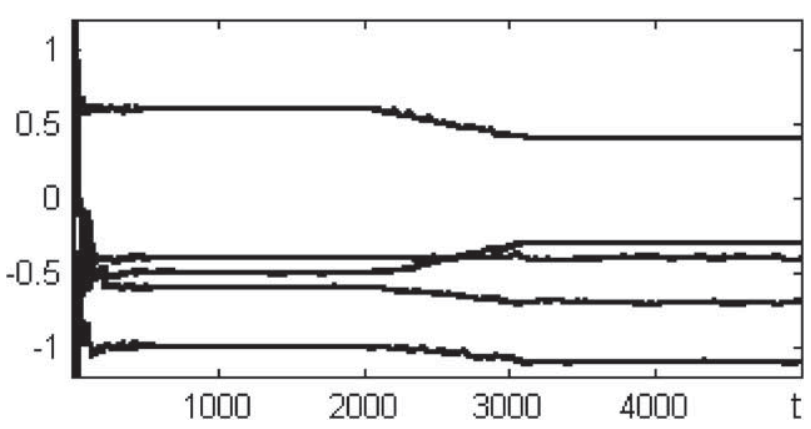

Fig. 5. Estimates of the nonlinear block parameters - Example 1.

The nonlinear block was given by the original piecewise-linear characteristic (the thin line in Fig. 6) that was changed to the new one (the thick line in Fig. 6). The corresponding sets of parameters are given in Table 2 .

The time-varying Wiener system generation and the recursive identification were performed under the same conditions as in Example 1. The process of parameter estimation is graphically shown in Fig. 7 for the linear block parameters and in Fig. 8 for the nonlinear block time-varying parameters. It can be seen that the model parameter estimates are able to track the true parameters also for this noninvertible nonlinearity.

Table 2

Parameters of the nonlinear block - Example 2

\begin{tabular}{lcc}
\hline Parameter & Original & Changed \\
\hline$m_{1}$ & -1.5 & -1.5 \\
$m_{R 2}-m_{R 1}$ & -0.8 & -1.0 \\
$m_{L 2}-m_{L 1}$ & 0.3 & 0.5 \\
$D_{R 1}$ & 0.8 & 0.6 \\
$D_{L 1}$ & -0.7 & -0.5 \\
\hline
\end{tabular}




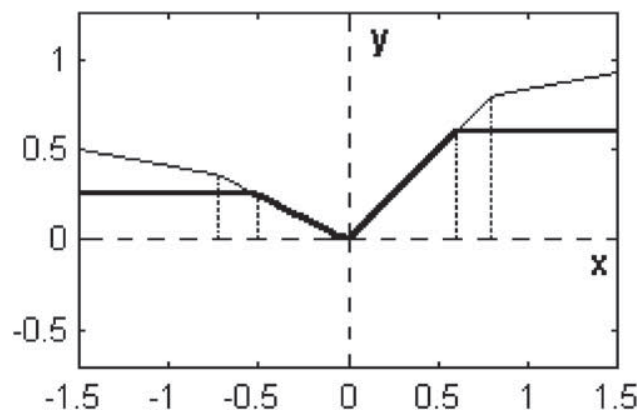

Fig. 6. Original (thin) and changed (thick) characteristic - Example 2.

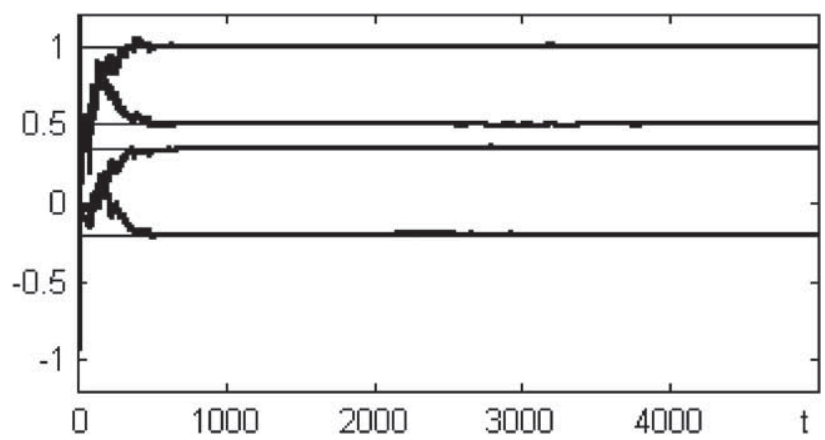

Fig. 7. Estimates of the linear block parameters - Example 2.

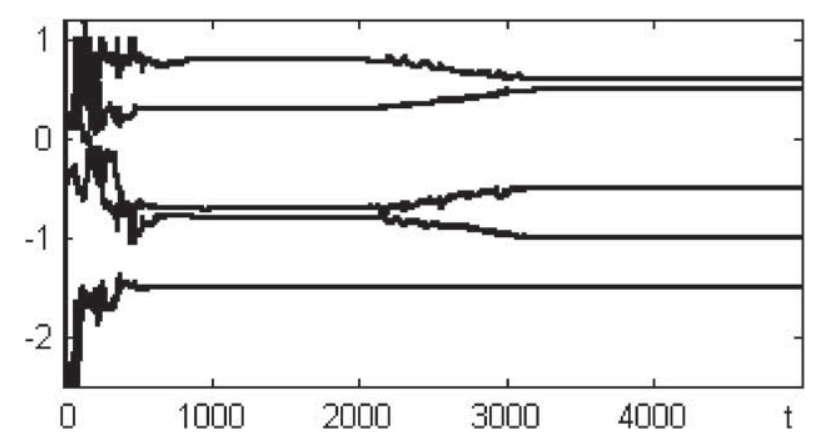

Fig. 8. Estimates of the nonlinear block parameters - Example 2.

\section{Conclusions}

A new approach to the recursive identification of Wiener systems with piecewise-linear characteristics has been presented that can be applied for a large class of dynamic systems having noninvertible output characteristics. All the model parameters to be estimated appear explicitly in the model description. It means that not only the linear block parameters but also the slopes of segments and the constants $D_{R 1}$ and $D_{L 1}$ determining the nonlin- 
earity domain partition, that may be time-varying, can be estimated.

The main application of this method is in on-line process monitoring and analysis but it can also be used in adaptive control algorithms. Although a convergence analysis has not yet been carried out, several specific examples have shown good convergence of the parameter estimates. Finally, note that the proposed recursive algorithm can be easily generalized for the more complex multisegment piecewise-linear characteristics (Vörös, 2007).

\section{Acknowledgment}

The author gratefully acknowledges financial support from the Slovak Scientific Grant Agency (VEGA).

\section{References}

Bai, E.W. (2003). Frequency domain identification of Wiener models. Automatica, 39, 1521-1530.

Bershad, N.J., Celka. P., Vesin, J.-M. (2000). Analysis of stochastic gradient tracking of time varying polynomial Wiener systems. IEEE Trans. Signal Processing, 48, 1676-1686.

Celka, P., Bershad, N.J., Vesin, J.-M. (2001). Stochastic gradient identification of polynomial Wiener systems: Analysis and application. IEEE Trans. Signal Processing, 49, 301-313.

Cerone, V., Regruto, D. (2006). Parameter bounds evaluation of Wiener models with noninvertible polynomial nonlinearities. Automatica, 42, 1775-1781.

Chen, H.F. (2006). Recursive identification for Wiener model with discontinuous piece-wise linear function. IEEE Trans. Automatic Control, 51, 390-400.

Chidambaram, M. (2001). Computer Control of Processes. CRC Press, New York.

Gerksic, S., Jurisic, D., Strmcnik, S., Matko, D. (2000). Wiener model based nonlinear predictive control. Int. J. Systems Science, 31, 189-202.

Greblicki, W. (1997). Nonparametric approach to Wiener system identification. IEEE Trans. Circuits and Systems - I: Fundamental Theory and Applications, 44, 538-545.

Haber, R., Keviczky, L. (1999). Nonlinear System Identification - Input-Output Modeling Approach. Kluwer, Boston.

Hasiewicz, Z., Sliwinski, P. (2002). Identification of nonlinear characteristics of a class of block-oriented nonlinear systems via Daubechies wavelet-based models. Int. Journal of Systems Science, 33, 1121-1144.

Hu, X.L., Chen, H.F. (2005). Strong consistence of recursive identification for Wiener systems. Automatica, 41, 1905-1916.

Janczak, A. (2005). Identification of nonlinear systems using neural networks and polynomial models: a blockoriented approach. In: Lecture Notes in Control and Information Sciences, Vol. 310. Springer, Heidelberg/Berlin.

Janczak, A. (2007). Instrumental variables approach to identification of a class of MIMO Wiener systems. Nonlinear Dynamics, 48, 275-284.

Jeng, J.C., Lee, M.W., Huang, H.P. (2005). Identification of block-oriented nonlinear processes using designed relay feedback tests. Industrial \& Engineering Chemistry Research, 44, 2145-2155.

Kalaš, V., Jurišica, L., Žalman, M., Almássy, S., Siviček, P., Varga, A., Kalaš, D. (1985). Nonlinear and Numerical Servosystems. Alfa/SNTL, Bratislava, Slovakia (in Slovak).

Korenberg, M.J., Hunter, I.W. (1999). Two methods for identifying Wiener cascades having noninvertible static nonlinearities. Annals of Biomedical Engineering, 27, 793-804.

Lacy, S.L., Bernstein, D.S. (2003). Identification of FIR Wiener systems with unknown, noninvertible, polynomial nonlinearities. Int. J. Control, 76, 1500-1507.

Lee, M.W., Huang, H.P., Jeng, J.C. (2004a). Identification and controller design for nonlinear processes using relay feedback. Journal of Chemical Engineering of Japan, 37, 1194-1206. 
Lee, Y.J., Sung, S.W., Park, S., Park, S. (2004b). Input test signal design and parameter estimation method for the Hammerstein-Wiener processes. Industrial \& Engineering Chemistry Research, 43, 7521-7530.

Ljung, L. (1987). System Identification: Theory for the User. Prentice-Hall, New Jersey.

Nordsjö, E., Zetterberg, L.H. (2001). Identification of certain time-varying nonlinear Wiener and Hammerstein systems. IEEE Trans. Signal Processing, 49, 577-592.

Park, H.C., Lee, J.L. (2006). Step and pulse response methods for identification of Wiener processes. AICHE Journal, 52, 668-677.

Pawlak, M., Hasiewicz, Z., Wachel, P. (2007). On nonparametric identification of Wiener systems. IEEE Trans. Signal Processing, 55, 482-492.

Pupeikis, R. (2005). On the identification of Wiener systems having saturation-like functions with positive slopes. Informatica, 16, 131-144.

Pupeikis, R. (2006). On the identification of Hammerstein systems having saturation-like functions with positive slopes. Informatica, 17, 55-68.

Sun, L., Ding, Y., Sano, A. (2003). Identification-based predistortion scheme for high power amplifiers. IEICE Trans. Fundamentals of Electronics Communications and Computer Sciences, E86A 4, 874-881.

Vörös, J. (2002). Modeling and parameter identification of systems with multisegment piecewise-linear characteristics. IEEE Trans. Automatic Control, 47, 184-188.

Vörös, J. (2007). Parameter identification of Wiener systems with multisegment piecewise-linear nonlinearities. Systems and Control Letters, 56, 99-105.

Wigren, T. (1993). Recursive prediction error identification using the nonlinear Wiener model. Automatica, 29 1011-1025.

J. Vörös received PhD degree from Slovak Academy of Sciences, Bratislava, Slovakia in 1983. He is a senior researcher at the Faculty of Electrical Engineering and Information Technology of Slovak Technical University, Bratislava. His research interests include the modeling and identification of nonlinear systems and also the mobile robot path planning using quadtree and octree representations of 2D/3D scenes.

\section{Sistemu su neinversiniais išvesties netiesiškumais rekurentinis identifikavimas}

\section{Jozef VÖRÖS}

Straipsnyje nagrinejjamas rekurentinis dinaminiu sistemu, turinčiu neinversines išvesties charakteristikas, identifikavimas. Tokios sistemos gali būti aprašomos Vinerio modeliu. Šio modelio speciali forma - tiesinis dinaminis blokas su sistemos funkcija ir netiesinis statinis blokas, aprašomas atkarpomis tiesine charakteristika, charakteringa neinversiniams netiesiškumams, esti duoto straipsnio tyrimo objektas. Pasiūlytas algoritmas šio modelio parametrams įvertinti. Šis algoritmas grindžiamas rekurentiniu mažiausiujų kvadaratu metodu, išplèstu vidiniams kintamiesiems skaičiuoti. Jis suteikia galimybę realiame laike ịvertinti abiejų identifikuojamų blokų parametrus ir ju pokyčius. Pasiūlyto metodo tinkamumas iliustruojamas pavyzdžiais, identifikuojant kintančias laiko atžvilgiu sistemas. 